\title{
LA CONSTRUCCIÓN CON LADRILLO ASENTADO EN BARRO. El CASO de la CIUdAd de Rosario
}

\author{
Adrián A. Pifferetti*
}

\begin{abstract}
Resumen
Al estudiar la fábrica de tierra romana de Tomas Fuhr en Remanso Valerio (1873-78) atribuimos su fracaso a los intereses asociados al cemento importado. La observación reiterada de las numerosas demoliciones realizadas en los últimos años en el centro de Rosario (y en otras localidades como Venado Tuerto y Lujan) nos han llevado a concluir que el fracaso de este y otros intentos como el de la Primera Argentina de Bialet Massé se debió no sólo a la competencia del cemento europeo sino también a la falta de una práctica concreta de construcción con argamasas o mezclas cementicias fuera de la obra pública y la religiosa. La experiencia de la ciudad de Rosario que creció prácticamente después de Caseros y que no nos ha dejado muestras de construcción en adobe, nos ha llevado a concluir que el mortero de barro para asentar ladrillos cocidos era de uso generalizado a fines del siglo XIX e incluso a comienzos del XX, subsistiendo, al menos en la confección de medianeras, paredes no portantes y tapiales y en la construcción suburbana, hasta la segunda o tercer década del mismo, al punto de ser considerada en los primeros Reglamentos de Edificación desde 1890.
\end{abstract}

Palabras clave: construcción, ladrillo asentado en barro, argamasa

\begin{abstract}
By studying the cement factory of Tomas Fuhr in Remanso Valerio (1873-1878) we attribute their failure to the associated interests on imported cement. The repeated observation of many demolitions carried out in recent years in central Rosario (and other locations as Venado Tuerto and Lujan) have led us to conclude that the failure of this and other attempts such as the Argentina Primera Bialet Massé it was due not only to the competence of the European cement but also to the lack of a concrete construction practice with mortars or cementitious mixtures out of public and religious work. The experience of the city of Rosario which grew almost after Caseros and has not left us samples of adobe construction has led us to conclude that the mud mortar to lay burnt brick was widely used in the late nineteenth century and even early twentieth, subsisting, at least in making walls, non-bearing walls and mud walls and suburban construction until the second or third decade of it, to the point of being considered in the first building regulations since 1890 .
\end{abstract}

Keywords: construction, based in mud brick, mortar

\footnotetext{
* Centro de Estudio de Materiales y Tecnologías, Universidad Tecnológica Nacional, Facultad Regional Rosario. Centro de Estudios de Arqueología Histórica. Universidad Nacional de Rosario. apiffere@gmail.com
} 


\section{Introducción}

Cuando tuvimos oportunidad, hace algunos años, de estudiar los restos de la fábrica de tierra romana de Tomas Fuhr, entonces aún subsistentes en Remanso Valerio (Granadero Baigorria), inmediatamente al norte del actual límite del ejido de la ciudad de Rosario, que funcionara entre 1873 y 1878 y fuera el primer intento de fabricación de cemento en el territorio argentino; atribuimos su fracaso a los intereses asociados al cemento importado. Dijimos entonces "el emprendimiento fracasó debido a la competencia desleal del cemento portland ingles introducido como lastre en las embarcaciones y a la competencia de otras fábricas locales como la de Julio Jaendel, que contó con la primer maquinaria a vapor para la producción cerámica" y también "la competencia desleal del cemento ingles Pórtland, tan evidente en los tejes y manejes alrededor del dique San Roque y las cales hidráulicas de Bialet Massé , en 1890, puede haberse evidenciado ya en esta época, aunque no hemos logrado encontrar información relativa a estos años". (Pifferetti, 2002 y 2004)

Nos basábamos en Frutos de Prieto (1985) que nos dice que la fábrica que había comenzado a producir tierra romana en 1872 sufrió posteriormente una reconversión "a raíz de la competencia.... con el cemento Pórtland introducido como lastre en las embarcaciones exportadoras de cereales" pasando a producir baldosas, tejas y caños cerámicos. También afirma que el fracaso en esta nueva actividad pudo deberse a la competencia de la fábrica a vapor de Julio Jaendel "aledaña a la residencia del Mariscal Andrés de Santa Cruz, en proximidades de la hoy ex estación del Ferrocarril Oeste Santafesino, situada en el Parque Urquiza"

Asimismo cuando se habla de los distintos intentos, todos frustrados, de fabricación de sustancias cementicias anteriores a la introducción del "cemento portland" (Fuhr, 1872; Dirección de Aguas Corrientes, Cloacas y Adoquinado de Barracas, 1876; Bialett Masse y Cassaffousth, 1885 y Derossi en Tandil, 1889) en general se lo atribuye a la competencia del cemento importado, véase lo escrito sobre la cuestión del primer dique San Roque (por ej. Frias 1985) o la página web de la Asociación de Fabricantes de Cemento Portland (http://www.afcp.org.ar/index3.php?IDM=12\&IDSM=6)

Sin embargo no encontramos evidencias de importación de cemento anteriores a 1880. Vedoya (1979) al analizar el comercio de importación y exportación para el período 1868-74 no nos habla de cemento ni nada que pueda interpretarse como tal. Carrasco recién especifica productos de importación o exportación en la cuarta edición de su Descripción Geográfica y Estadística de la Provincia de Santa Fe (1886). Aparece allí entre las principales importaciones sujetas a derechos del puerto de Rosario en el año 1885, 1.629.305 Kg de "tierra hidráulica" por valor de $37.316 \$ \mathrm{~m} / \mathrm{n}$; y una mucho menor cantidad para el de Santa Fe $(25.640 \mathrm{Kg})$ un año antes.

La observación de las numerosas demoliciones realizadas en los últimos años en el centro de Rosario (y en otras localidades como Venado Tuerto y Lujan) nos han llevado a concluir que, si bien no se puede negar la existencia de prejuicios y la orquestación de una verdadera campaña de desprestigio para desacreditar al cemento elaborado en la Primera Argentina por Bialett Masse y utilizado por Cassaffousth en la construcción del primer dique San Roque, el fracaso de esos primeros intentos de industrialización se debió no sólo a la competencia del cemento importado sino también a la falta de costumbre en su utilización, ya que el mortero de barro era de uso generalizado a fines del siglo XIX e incluso a comienzos del XX, subsistiendo, al menos en la confección de medianeras y tapiales y en la construcción suburbana, hasta la segunda o tercer década del mismo.

\section{Construcción en Tierra}

Recordemos que la unión de los materiales de construcción se realiza con la ayuda de productos maleables que reciben el nombre genérico de argamasas o morteros que, al secarse, se endurecen y dan solidez a la obra. Estos productos se preparan con elementos como el cemento, la cal y el yeso. 
Su uso es esencial en construcción ya que es el material con el que se pegan los bloques de construcción como ladrillos, piedras, bloques de hormigón etc. Además, se usa para rellenar los espacios que quedan entre los bloques y para revocar las paredes.

Desde tiempo inmemorial en nuestra zona, ante la falta de piedra y maderas duras, la construcción se basó en el barro y la quincha, es decir se recurría a los materiales que abundaban: tierra, palos y los pastos y juncos de las costas. En la época colonial se usaron los distintos tipos de tapia y el adobe en la construcción y con posterioridad el ladrillo cocido asentado en barro.

Una buena idea del tipo de construcción utilizado a fines del siglo XIX y comienzos del XX lo suministra Lambert (2004) al referirse a los almacenes de ramos generales de la campaña de la provincia de Buenos Aires:

"Sus construcciones - de marcado estilo italiano- de líneas simples, estaban compuestas por paredes de ladrillo cocido de $30 \mathrm{~cm}$ por $15 \mathrm{~cm}$ por $5 \mathrm{~cm}$ asentados en barro amasado y pisado por caballos, llegando ellas hasta un espesor de $45 \mathrm{~cm}$, elevadas sobre cimientos del mismo material de $60 \mathrm{~cm}$ de base.

Las paredes llegaban a una altura de 4,50 a 5,00 metros en la que se construía un cielorraso tipo bovedilla, de ladrillos tejuelas montados sobre una estructura de vigas de pino tea de $3 \mathrm{x} 9$ pulgadas y alfajías transversales de 1,5 x 3 pulgadas. Estos ladrillos, que dispuestos "de plano" o "de panza" sobre la estructura de madera formaban un techo aislante, eran unidos en su cara de arriba con una capa de barro, capa aislante que, junto con el ladrillo, aplacaría los rigores de las altas o bajas temperaturas que desde el exterior transmitiría el techado de chapas de zinc que era montado de una estructura de madera -cámara de aire mediante- sobre el cielorraso. En algunas construcciones se ha encontrado por sobre esa capa aislante de barro y ladrillo, un techado de cerámica azotea, y recién sobre éste, el techado de zinc.

Por sobre la altura del techo, las paredes se prolongaban en sólidas cargas que terminaban con cornisas delicadamente ornamentadas con molduras, salientes y barandales con columnas o alabastros.

Los revoques interiores, -imprescindibles para la higiene y buena imagen del local- estaban hechos a la cal "apagada" y mezclada con polvo de ladrillo fino. Los exteriores se realizaban con arena fina, cemento blanco, cemento negro y cal apagada."

En Buenos Aires, donde en las últimas décadas se han realizado cierto número de trabajos de arqueología urbana se ha podido afirmar "El barro es el material más antiguo, barato y simple y las paredes y cimientos unidos con él son innumerables entre la Fundación y el siglo XVIII. Prácticamente a partir de los inicios del siglo XIX ya no hubo en la ciudad paredes unidas con barro, y podemos considerar que para la mitad de ese siglo empezaron a desaparecer. Sí se usó para cimientos, pero también la imposición de normas más estrictas y controles a la construcción fue prohibiéndolas. Es evidente al excavar que los albañiles sabían preparar diferentes tipos de barros" (Schávelzon, 1991:218). Y también "las casas construidas durante todo el siglo XVII y parte del XVIII fueron en su mayoría de tapias, aunque ya había algunas de ladrillo; desde el siglo XVII temprano muchos techos se hacían de tejas, también se usó el adobe y más adelante el ladrillo asentado en tierra" (Schávelzon (1999:216). Para la época de construcción del Caserón de Rosas,

(...) todavía era habitual en la ciudad la construcción con ladrillos asentados en barro, aunque lentamente se iba difundiendo la cal y se fueron abaratando los costos, por lo que para el final del siglo XVIII todos los grandes edificios urbanos tenían no sólo sus juntas hechas de ese material sino también el blanqueo inicial. (Schávelzon y Ramos, pp. 2009:96).

Lopez Coda (2005) al referirse a la Casa Mínima dice que "los muros están construidos íntegramente con materiales porosos (ladrillo con mortero de barro, revoque de bosta y blanqueo a la cal) por lo tanto son muy permeables, permitiendo de esta manera que la humedad no se acumule provocando 
deterioros" (p. 96). Por su parte Moreno (1995) afirma coincidentemente que "el uso de los morteros de cal se extendió hasta mediados del siglo XIX" y que "aún en pleno siglo XX se encuentran paredes asentadas en barro, en medianeras de las "casas chorizo"" (p. 51).

Sin entrar a analizar el uso de mezclas de cal y barro citados por Schavelzon (1995 y 2005), ni el uso de morteros en que al cemento se le agregaba barro en lugar de arena (Volpe Soccorso, comunicación personal, 2016), consideraremos el uso de barro como ligante de ladrillos de tierra cocida.

En cuanto a la ciudad de Santa Fe Chiappero y Supisiche (2003) nos dicen que:

El uso del ladrillo cocido asentado en barro [junto al adobe] comenzó a difundirse con las influencias italianizantes del período republicano y confederal en los cuales se utilizaron ambas tecnologías en edificaciones como la casa del Brigadier General Estanislao López. Pero poco a poco el adobe fue reemplazado por el ladrillo en las obras más significativas del período liberal. La arquitectura doméstica mantuvo su ligazón con las técnicas y materiales constructivos de menor calidad aunque para las primeras décadas del siglo XX los ladrillos asentados en mezcla de cal y arena se habían constituido en elementos primordiales de todo tipo de construcción. (p.22)

En nuestra infancia recordamos abundantes casos de casas de ladrillos vistos asentados en tierra en la zona en parte urbana en parte semirural del barrio Las Delicias, Puente gallegos y estación Hume.

Rosario como centro urbano comienza a desarrollarse a mediados del siglo XIX, después de la batalla de Caseros. El diario El Orden de Buenos Aires nos dice en 1855:

El Rosario hace tres años no era más que una aldea, contando a lo más medio centenar de casas de ladrillo y ranchos diseminados, habitados por unos pocos cientos de familias. Hoy es una pequeña ciudad de unos 10.000 habitantes en donde el rancho casi ha desaparecido, cediendo el lugar a blancas casas de ladrillo (...). (Revista de Historia de Rosario, 1996, p.14)

El empadronamiento confederal indicaba que en 1858 Rosario tenía 19 casas de pisos con azotea, 10 casas de dos pisos con tejas, 530 casas de un piso y azotea, 758 casas de un piso y tejas, 411 ranchos de adobe y paja, lo que hacía un total de 1728 unidades de vivienda. (Mader, 1968, p.5)

Tengamos en cuenta que estas cifras se refieren a todo el departamento que entonces comprendía a toda el área provincial al sur del río Carcaraña, comprendiendo los actuales departamentos San Lorenzo, Caseros, Gral. López y Constitución.

Cuando se realiza el primer censo nacional (septiembre de 1869) la misma área geográfica tiene 3775 casas habitables: una de tres cuerpos, 66 de altos, 1607 casas de un cuerpo, 7 casas de tejas de un cuerpo, 3 casas de madera de dos cuerpos, 228 casas de madera de un cuerpo, 1863 casas de paja de un cuerpo; las de paja y barro siguen representando casi la mitad" (Dócola, 1994; Álvarez, 1943).

Para la década del 80 Alvarez nos dice si bien se edifica mucho abundan quienes lo hacen con ladrillo asentado en barro y techos de hierro galvanizado. Citaremos con alguna extensión una breve nota publicada por el historiador Mikielievich (1977), ya que nos precedió más de medio siglo en la observación de las demoliciones de la ciudad, y suministra importante información sobre la producción de ladrillos durante la época de mayor auge expansivo de la ciudad:

La construcción de edificios en los comienzos de la formación urbana de nuestra ciudad se hizo con ladrillos y adobes asentados en barro. El primer edificio construido en regla -de cuya existencia da cuenta un documento de 1763- perteneció al maestre de campo Pedro Pascual Acevedo y estuvo ubicado en la esquina sudeste de las calles Buenos Aires y Córdoba. Se hizo con ladrillos y adobes cuyo peso oscila alrededor de 8,600 gramos la unidad miden 43 x 20 x 6,5 cm y se colocaron alternadamente, según lo comprobamos en 1946, al extraerse restos de muros de la casa que allí existía, demolida por entonces. De estos ladrillos, como de todos los mencionados en esta nota, conservamos unidades. (p.75) 
Otros ladrillos del siglo XVIII los retiramos en 1970 de la demolición de la casa del doctor Juan Alvarez,...ubicada en la esquina suroeste de las calles Córdoba y 25 de Diciembre. Se encontraron debajo de los pisos del edificio que para su residencia familiar había hecho construir en 1913 el aludido historiador, sobre el solar de la casa que fuera del historiógrafo Pedro Tuella. Estos ladrillos tienen formato $39 \times 18 \times 5,5 \mathrm{~cm}$.

Al promediar el siglo XIX, con la afluencia de alarifes y albañiles europeos se intensifica la construcción de edificios, en su casi totalidad de planta baja. La residencia Bella Vista, que adquiriera en 1857 el mariscal Santa Cruz al coronel José Ma. Pita, donde hoy existe la plazoleta de ese nombre, se levantó con ladrillos de $42,5 \times 20 \times 6 \mathrm{~cm}$, medidas superiores a las de ladrillos utilizados en construcciones realizadas posteriormente, los que, por otra parte, no guardan uniformidad, midiendo $40 \mathrm{x}$

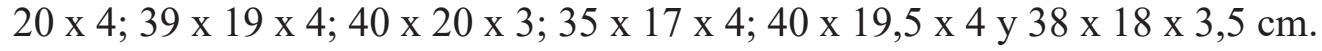

La fabricación en gran escala de ladrillos la inició en febrero de 1853 el vecino alemán Enrique Napp, estableciendo hornos en los alrededores de la ciudad donde hasta entonces existían quintas. En 1869 funcionaban 46 hornos en los suburbios, quemándose en el primer semestre de ese año más de cinco millones de ladrillos, sin incluir los fabricados por una máquina a vapor emplazada por la empresa del Ferrocarril Central Argentino en su estación local. Esta producía de doce a quince mil unidades por día...Por esos años el vasco Juan Primero Juanto, con hornos en San Francisquito, era considerado uno de los principales fabricantes. En 1889 comenzó a funcionar una planta industrial para la fabricación de ladrillos en las inmediaciones del kilómetro 9 del Ferrocarril Oeste Santafesino, al noroeste de las actuales avenidas Provincias Unidas y Godoy. Pertenecía a la sociedad anónima La Nacional..."

Si nos fijamos en las más antiguas imágenes fotográficas de la ciudad como el albúm de vistas de Alfeld de 1866 y el de autor anónimo 1 que se le ha atribuido la fecha de 1888 los ranchos que aparecen son evidentemente de diversos materiales.

Ampliando las áreas de interés de las fotografías...podemos deducir que tal como lo describen los viajeros y se desprende de las categorías censales los materiales con que se construían los ranchos eran variados y si bien podía clasificárselos en ranchos de barro, de paja y de madera; muchos mostraban más de un material. Algunos parecieran ser de ladrillos o de adobes. (Pifferetti, 2009, p.571).

Para el asentado de los adobes o ladrillos, se utilizaban morteros de barro de la misma composición de los adobes, pero con relación volumétrica: 3 de tierra, 1 de arena gruesa y 1 de paja. Lopez Coda (2005) nos dice que el revoque con barro batido y bosta blanqueados a la cal, antes citado "es característico de las construcciones coloniales y se usó hasta 1860/70, cuando fue prohibido, al igual que los muros de adobe, por razones de higiene"

Sin embargo en Rosario no se ha conservado ninguna muestra del uso del adobe, hasta el punto de que entre los profesionales de la construcción se tiende a denominar "construcción de adobe" a la de ladrillos asentados en barro, que si abunda en añosas construcciones del centro y los barrios.

Socorso Volpe que viene efectuando trabajos de arqueología urbana en Rosario desde la década de 1960, nos dice que la construcción con medianeras se inicia alrededor de 1830, más o menos con la reconstrucción subsiguiente al incendio de Rosario por parte de Lavalle.

En lo que denomina "primera manzana" es decir la de rodea a la catedral individualiza varios muros: Cimientos de muro medianero. Estaba asentado sobre tierra batida y en algunos sectores fragmentos de ladrillo (cascotes) y adobe como contrapiso (se encontraron solamente dos hiladas) construido en paralelo (tres ladrillos por hilada) formando pared de $60 \mathrm{~cm}$. Mezcla de cal y barro. Los ladrillos estaban enteros y fragmentados con dimensiones variables de 43 x 20 x 6,5; 43 x 20 x 6; $40 \times 20 \times 6$; $38 \times 20 \times 7 \mathrm{~cm}$." Y el brocal de un pozo enterrado bajo tierra y escombros por debajo de una estructura cloacal de 1880-90. Los ladrillos son de 39 x 19 x $5 ; 40$ x 20 x 5; 38 x 17 x 4,5 y 
35 x 18 x 4,5 cm; "la mezcla ligante de barro batido con alto contenido orgánico y polvo de ladrillo (Volpe, 1999).

Cimientos de paredes de una habitación, lindante a la medianera,(un pequeño cuarto de aprox. $4 \times 4 \mathrm{~m}$ ) Sus tres paredes (salvo la medianera, ya descripta) estaban construidas de la misma forma, es decir en hiladas "en travertino" (canto y largo alternado), formando pared de $45 \mathrm{~cm}$, ladrillos homogéneos en calidad y tamaños, muy bien cocidos $(26 \times 12 \times 5 \mathrm{~cm})$.La mezcla formada en base a cal , arena y cemento (tanto portland como tierra romana), el contrapiso estaba hecho de escombros y cementado. En una de las paredes, (que linda con la medianera), parte de la misma estaba reciclada, contenía restos de una construcción anterior, ya que en la misma se observaban ladrillos de otras dimensiones $(43 \times 20 \times 6 \mathrm{~cm}$ y 40x20x5cm) y construcción en paralelo (Volpe, 2000).

\section{Reglamento de Edificación}

En el Reglamento de Edificación de 1890 se establece por un lado que "los muros de fachada deberán ser asentados en cal” (Art. 83) y que "dentro de los límites de las calles Corrientes, Tucumán, calle del bajo, Mendoza y 25 de Diciembre no se podrá utilizar ni el barro ni la madera tanto en la calle como en el interior" (Art. 84). En cuando a la reforma y ampliación de construcciones existentes en sucesivas modificaciones (hemos podido consultar las aportadas en 1957, Dto. 47615/73 y Ord. 4975/90, todos coincidentes) se establece en el item 3.8.1-4 Construcciones existentes de barro: "Los edificios construidos en barro con anterioridad a la sanción de este Reglamento podrán ser refaccionados siempre que sus muros no tengan una altura mayor de $6 \mathrm{~m}$, no se aumente la superficie cubierta y no se carge sobre los mismos" y en el item 4.7.7 Uso de muros existentes, 4.7.7.2 Caso de muros existentes asentados en barro, se agrega que:

Se permitirá utilizar

a. Un muro divisorio existente en barro en buen estado, de 0,45 $\mathrm{m}$ o más de espesor, siempre que su altura no sea mayor de $6 \mathrm{~m}$.

b. Un muro existente de $0,30 \mathrm{~m}$ de espesor asentado en barro siempre que se halle en buen estado de estabilidad y no tenga una altura mayor de $4 \mathrm{~m}$.

c. En cualquier caso el muro divisorio no podrá usarse como pared de carga y como terminación tendrá las dos últimas hiladas asentadas con mezcla de cal o cemento revocada.

\section{Ladrillo Asentado en Barro en Rosario}

El uso del ladrillo asentado en barro la hemos constatado en las siguientes demoliciones de la ciudad:

1. Laprida entre 857 y 875 , manzana que da a plaza 25 de mayo. Medianeras y frente

2. Córdoba 641 manzana lateral a la anterior, enfrentada a la que Volpe denomina "primera manzana". Medianeras y frente

3. San Luis 547/551 Medianera y frente

4. 9 de Julio 1186 medianera y frente

5. 3 de Febrero 1100 medianera

6. Mendoza 940 medianera

7. Mendoza 841/49 medianera

8. Catamarca 1500 , esq. Pte. Roca. Pared frontal

9. Rueda 1053. Medianera

10. Muro perimetral de los talleres del F. C. Central Argentino sobre calles Canning y Junín

11. Prolongación Oroño entre Ombú y Madre Cabrini 
12. Buenos Aires 990 .

Y en estas construcciones:

1. Bar Londres Maipú 902 /06. Paredes frontales, espesor aproximado $60 \mathrm{~cm}$

2. Maipú 1175 Medianera

3. San Luis 846Alianza Francesa. Medianera

4. Sarmiento 2859 Medianera

5. Rodríguez 138 bis muro de cierre

6. Riobamba 200bis muro cierre

7. Corrientes 1889, casi esquina Pasco. Pared frontal.

8. $\quad$ Mitre 1800

Resulta muy interesante la antigua edificación de lo que fuera el bar Londres en la esquina SW de Maipú y Rioja, actualmente cerrada y en remodelación. Allí, como elemento decorativo, se había quitado el revoque en una zona de la pared que daba a la calle Rioja poniendo al descubierto una pared de ladrillos asentados en barro. La ochava, remodelada externamente en época indeterminada, posiblemente ya en el siglo XX, muestra en la parte superior la inscripción en bajo relieve "fundado en 1850" Bar Londres y se observan además varios signos adicionales de antigüedad como el espesor de las paredes, el derrame interior de los vanos "que permitía abrir correctamente las carpinterías hacia adentro, iluminando mejor el ambiente por la refracción de la luz que allí se producía" (López Coda, 2005, p.96), el dentado de la cornisa exterior y el techo de tirantería de madera.

La casa de la calle Maipú 1175, correspondiente al tipo que Juan Alvarez denomina "modelo de casa de época según el Reglamento de edificación municipal” y “características de 1900”. "Quienes solo disponen de recursos para edificar casa de una planta, dejan construido el balcón para lo que, Dios mediante, será otro piso. El techo actual no remata la obra: es mera etapa provisoria" (Alvarez, 1943, p.423). En esta al efectuarse obras en la edificación que la flanquea por el norte, y como la línea de edificación es más interna, se evidencia al haber sido afectado el revoque de la medianera, que se trata de una pared de ladrillos asentados en barro y con revoque a su vez de barro, luego encalado (Figura 1). Hoy esto ha quedado cubierto por una capa de baldosas cerámicas.

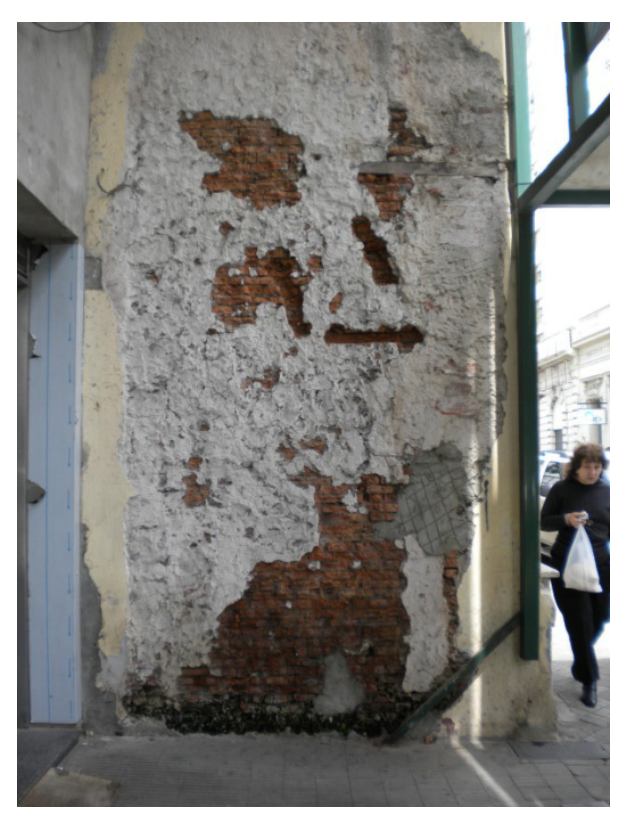

Figura 1. Medianera de Maipú 1100 
Una tercera manifestación de ladrillos asentados en barro con un aparejo muy complejo observamos en la Alianza Francesa, San Luis 846, que con su salón de actos avanza en el centro de manzana, por gentileza de su director F. Davanture. Se trata de una pared de separación con dos propiedades aledañas con frente a la calle Laprida (Figura 2).

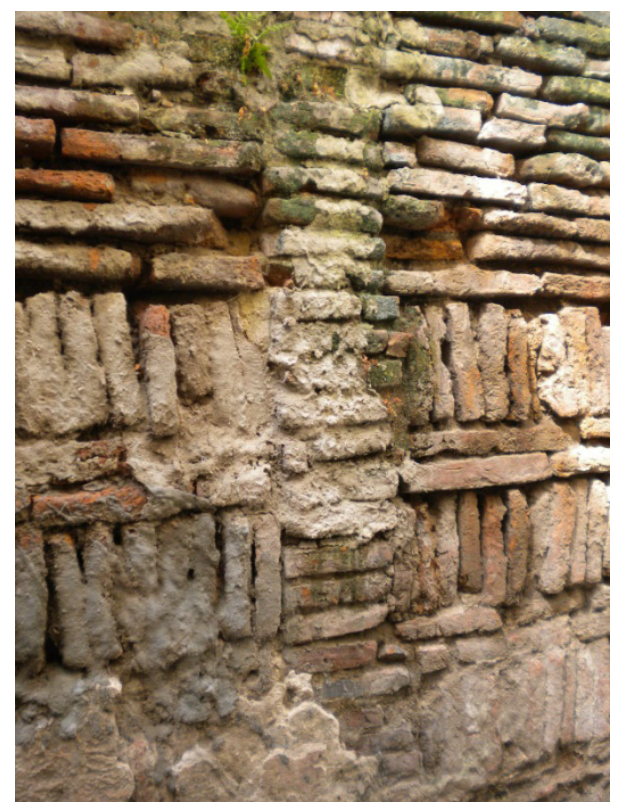

Figura 2. Medianera en San Luis 800

Es de destacar que los tres ejemplos dados se encuentran en la zona en que el Reglamento de Edificación del año 1890 establecía, como dijimos "no se podrá utilizar ni el barro ni la madera tanto en la calle como en el interior". Por lo que la norma no se cumplía o los ladrillos asentados en barro no se consideraban como construcción en barro o, lo que es más probable, se trata de construcciones preexistentes refaccionadas en mayor o menor medida.

Otros casos los hemos ido detectando en las demoliciones, que en nuestra ciudad siempre han sido abundantes. En dos de ellas, situadas dentro de la zona de exclusión del barro hemos detectado la presencia de fachadas de paredes asentadas en barro. Se trata de la construcción de arquitectura "italianizante barroca" de Córdoba 641, que enfrenta calle mediante el área de excavación de Volpe detrás del ábside de la catedral, en la que llama "primera manzana y dista, por consiguiente media cuadra de la plaza central de la antigua ciudad. En este caso tanto el frente como las paredes interiores son del tipo que analizamos, como puede observarse en la figura 3. La otra a poca distancia, es una muy antigua construcción que existía en Laprida al 800 con techos de tirantería de madera en una de las primeras manzanas de la ciudad, lindera por el este con la citada plaza 25 de Mayo y en la que estuvo ubicada la jefatura política donde hoy se encuentra el Correo Central. En este caso también pudimos observar que todas las paredes presentaban argamasa de barro y que los ladrillos eran más finos que los actuales.

En otra demolición dentro de la zona de prohibición de 1890, hemos detectado el barro en medianeras es el caso de Mendoza 800, donde la retracción de la línea de edificación contemporánea permitió la supervivencia durante un tiempo de parte de una pared medianera de estas características). Otra medianera asentada en barro pudimos observar hace algunos años en Mendoza al 900 pero en la vereda de enfrente a la zona vedada.

Ya fuera del área de 1890 citaremos una medianera que ha subsistido parcialmente en San Luis al 500, entre la cochera de un edificio de propiedad horizontal y otro que está hoy en construcción. 

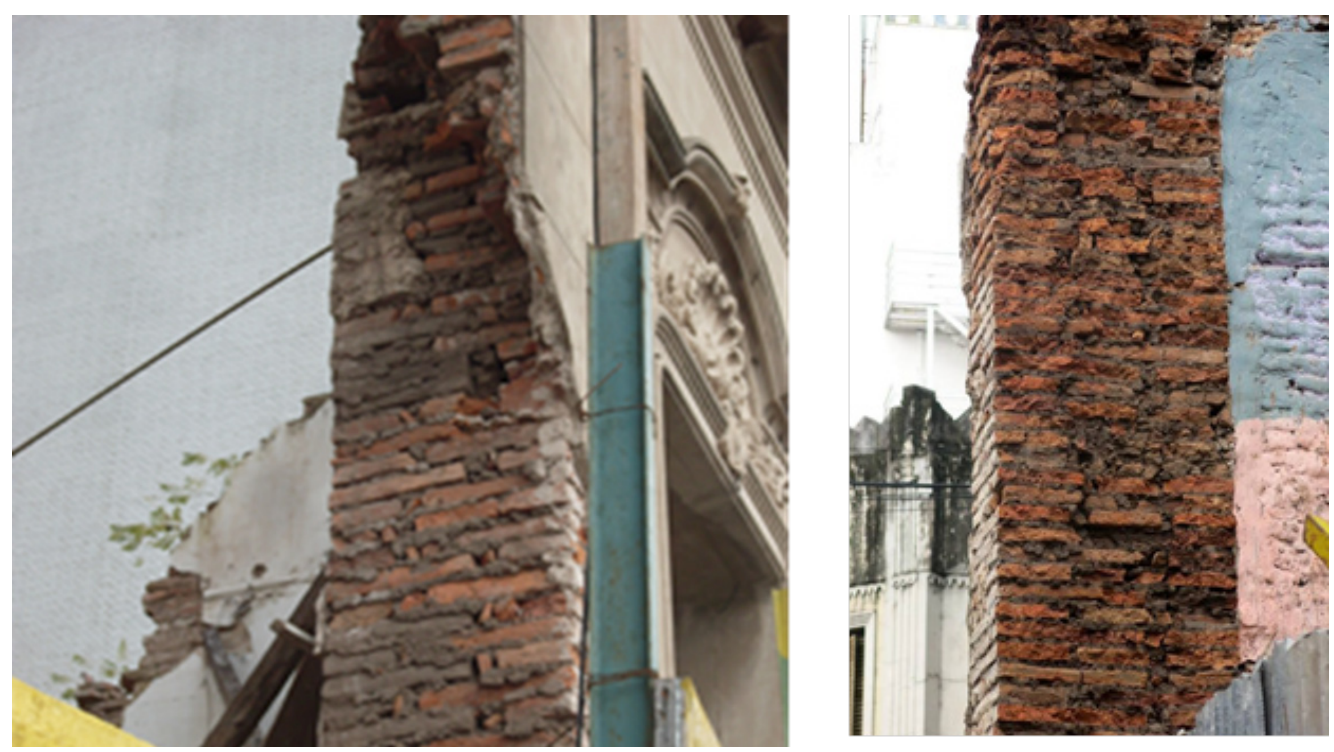

Figura 3. Fachadas de ladrillos asentados en barro a) Córdoba 600, b) Buenos Aires 990

Esta pared tiene ladrillos de dimensiones 40 × 20 × $4 \mathrm{~cm}$. 6; una fachada en 9 de Julio 1100, una medianera en 3 de Febrero a la misma altura y un muro frontal en Catamarca al 1500, esquina NE con Pte. Roca).

Ya en zonas industriales alejadas del centro lo hemos encontrado en un muro de cierre en Rodriguez 100 bis, en inmediaciones de la Estación Rosario Norte (F.C. Buenos Aires-Rosario); en el muro de cierre de los talleres del F.C. Central Argentino sobre Canning y Junín (ladrillos de 28 x 14 x 4,5, $29 \times 13,5 \times 4 \mathrm{~cm}$ ); en un pared de un terreno de Rueda al 1000, que según los vecinos más antiguos formó parte de una "alta construcción", en la zona de la Estación Rosario de la Compañía General de ferrocarriles en la Provincia de Buenos Aires (hoy Gendarmería Nacional); la medianera de lo que resta de una vieja casa en Sarmiento 2859; un muro de cierre de Riobamba 200bis y la pared de una propiedad demolida parcialmente al abrir la doble traza de Bv. Oroño al 5600.

\section{Aparejo de los Ladrillos}

Se denomina fábrica a la manera de colocar los ladrillos en sentido longitudinal ó trasversal, uno sobre otros o solapados. El sistema empleado para disponerlos o trabarlos recibe el nombre de aparejo. Aclaremos que en un ladrillo prismático se denomina tabla a la cara mayor, soga o canto al lateral más largo y tizón o testa al más corto. Tradicionalmente el aparejo se forma colocando el ladrillo de plano, es aparejo a soga si muestra este lado al frente, a tizón si en cambio es este y de tizón y soga si es combinado. El aparejo a panderete es la pared de ladrillos mostrando la tabla, utilizada en muros de poco espesor y aparejo a sardinel aquel en que están puestos de canto y uno a continuación de otro pegados en toda la extensión de su cara mayor.

En algunos de los casos citados hemos encontrado un aparejo complejo formado por una o dos hiladas horizontales de ladrillos de canto alternadas con una hilada de sardinel mostrando el tizón o lado corto. Este tipo de disposición es totalmente desusada hoy y podría responder a dos razones: un ahorro en el número de ladrillos para completar la pared o un aumento en la resistencia mecánica, aunque algunos ingenieros civiles consultados ponen en duda que esta se incremente realmente.

Particularmente interesante resulta la pared de la figura 3 ya que presenta una serie de pilares del mismo espesor que el resto del muro por lo que su utilidad es dividir la continuidad en distintos 
paños, de modo de que si uno cediera, el colapso quedaría circunscripto a este elemento. Además el aparejo de dos hiladas de ladrillos de plano alternados con una de sardinel llega hasta media altura, siendo la mitad superior de ladrillos planos. Siendo mayor el peso de pared en la parte inferior que en la superior, es indudable que quien la proyecto quiso darle mayor resistencia a la mitad inferior.

\section{Consideraciones finales}

Debemos llegar a la conclusión dado la gran cantidad de evidencias del uso de arquitectura de ladrillo asentado en barro en rosario que hasta fines del siglo XIX fue común su uso en la construcción de viviendas particulares, digamos para ser más exactos hasta la adopción de Código de Edificación de 1890, incluso en la zona externa a la indicada en el mismo se siguió usando hasta las primeras décadas del XX se siguió usando especialmente en las medianeras. En los barrios alejados y zonas de quintas donde iba llegando la ciudad esto se mantuvo hasta casi mediados de siglo. Idéntico método constructivo lo hemos notados en antiguas construcciones subsistentes o demolidas en poblaciones de la región como Venado Tuerto, Pergamino o Luján, no notando diferencias entre las de la provincia de Santa Fe y las de la de Buenos Aires aunque algunas de ellas podían provenir de la época en que la provincia de Buenos Aires estuvo separada de la Confederación Argentina.

Alrededor de 1900 la importación de cemento Portland y la fabricación local de tierra romana comenzó a modificar la modalidad constructiva tanto en las obras públicas como en las de los inmigrantes europeos. Un ejemplo de ello es la utilización de tierra romana de la fábrica de Tomas Fuhr en la construcción de la Jefatura Política en la esquina de Córdoba y Buenos Aires y de los puentes del Arroyito sobre el arroyo Ludueña y el segundo puente Gallegos sobre el Saladillo; así como en la construcción de las casas de las colonias agrícolas como Esperanza.

Otra observación interesante es notar que los constructores y albañiles que eran de origen europeo, principalmente italianos acostumbraban construir los aparejos entrecruzando la orientación de los ladrillos (ver figura 3) como acostumbraban hacer en su tierra de origen aunque esto no implique un aumento de la resistencia mecánica de la pared sino una mayor capacidad para soportar sacudidas sísmicas, cosa no necesaria en estas regiones.

\section{Referencias}

ÁlVAREZ, J. (1998). Historia de Rosario (1689-1939). Rosario: UNR Editora

CARRASCO, G. (1886). Descripción geográfica y estadística de la Provincia de Santa Fe. Buenos Aires: Imp. Stiller Laass

CHAPPERO, R. O. y SUPISICHE M. C. (2003). Arquitectura en tierra cruda. Buenos Aires: Nobuko

DÓCOLA, S. (1994). Fotografía y ciudad, Alfeld y Rosario en 1866. En: $4^{\circ}$ Congreso de Historia de la Fotografía: 155-160. Buenos Aires: Círculo Médico de Vicente López.

FRUTOS DE PRIETO, M. (1985). Evolución Industrial de Rosario. Desde sus orígenes hasta 1900. $3^{\text {a }}$ Parte. Revista de Historia de Rosario, XXIII (37). Rosario: Sociedad de Historia de Rosario: 2353.

LOPEZ CODA, P. (2005). La casa mínima: una historia y una leyenda. En Los conventillos de Buenos Aires. En Schávelzon D. (Coord.) La casa mínima, un estudio arqueológico. Buenos Aires: Ed. ET. 67-102. 
MAEDER, E. J. (1968). El Censo Confederal. Separata de Trabajos y Comunicaciones. La Plata MIKIELIEVICH W. C. (1977). Antecedentes sobre el ladrillo. Revista de Historia de Rosario XV (29) 75-76.

MORENO, C. (1995). De las viejas tapias y ladrillos. Buenos Aires: ICOMOS Comité Argentino.

PIFFERETTI, A. A. (2002). La fábrica de tierra romana de Remanso Valerio. [CD-ROM]. Jornadas de Historia de Rosario. Rosario: Municipalidad de Rosario.

PIFFERETTI, A. A. (2004). La fábrica de tierra romana de Tomás Fuhr: la primera productora de cemento del país. [CD-ROM] Miradas al pasado desde Chivilcoy. Chivilcoy: $\mathrm{CECH}$.

PIFFERETTI, A. A. (2009). La fotografía antigua como herramienta de identificación de la arquitectura del siglo XIX y comienzos del XX. El caso de la ciudad de Rosario. En Marini Y., Pérez Zavala G. y Aguilar Y. (Comp.) Las sociedades de los paisajes áridos y semiáridos del centro-oeste argentino. 565-575.

SCHÁVELZON, D. (1991). Arqueología histórica de Buenos Aires I. La cultura material porteña de los siglos XVIII y XIX. Buenos Aires: Corregidor.

SCHÁVELZON, D. (1994). Arqueología e historia de la imprenta Coni, Buenos Aires. Arqueología Histórica en América Latina 1. Columbia: University of South Carolina.

SCHÁVELZON, D. (1999). Arqueología de Buenos Aires. Buenos Aires: Emecé.

SCHÁVELZON, D. (2005). Arqueología de un conventillo porteño. En Schávelzon, D. (Coord.) Los conventillos de Buenos Aires. La casa mínima, un estudio arqueológico. Buenos Aires: Ed. ET. 103142.

SCHÁVELZON, D. y RAMOS, J. (2009). El caserón de Rosas. Historia y arqueología del paisaje de Palermo. Buenos Aires: Corregidor.

VEDOYA, J. C. (1979). La magra cosecha 1868-1874. Colección Luna, F, (Dir.) Memorial de la Patria. Buenos Aires: La Bastilla.

VOLPE, S. (1999). Asentamientos españoles tardíos: Los pagos (Excavación del sitio Plta. E. Bertolé, Rosario). Actas XII Congreso Nacional de Arqueología Argentina. La Plata: U. N. de La Plata.

VOLPE, S. (2000). Arqueología de salvamento. La primera manzana. El Rosario temprano (17901820). II ${ }^{\circ}$ Congreso Virtual de Antropología y Arqueología NAyA. Recuperado de http://www.naya. org.ar/congreso2000/ponencias/Soccorso_Palma.htm

Recibido: 02/05/2017

Aceptado: 08/07/2017 